\title{
Tissue and serum pepsinogen I and II in gastric cancer identified using immunohistochemistry and rapid ELISA
}

\author{
N Konishi, K Matsumoto, Y Hiasa, Y Kitahori, I Hayashi, H Matsuda
}

\begin{abstract}
Aims-To investigate the immunohistochemical expression and the serum concentrations of pepsinogen $I$ and $I$ in different histological types of gastric cancer as compared with other gastric disorders.

Methods-Formalin fixed, paraffin wax embedded tissue specimens of 38 gastric cancers obtained from surgical cases were used for the immunohistochemical studies performed with the avidin-biotin complex method using monoclonal antibodies against purified pepsinogen I and II. Pepsinogen concentrations from serum obtained from the above patients, from patients with various other gastric disorders, and from normal controls were measured with a rapid non-radioactive one step enzyme linked immunosorbent assay (ELISA).
\end{abstract}

Results-Eight of 38 (21\%) and seven of 38 (18\%) gastric carcinomas showed immunoreactivity to pepsinogen I and pepsinogen II, respectively, without any correlation to histological classification or differentiation. Decreased pepsinogen I concentrations and low pepsinogen I : II ratios were found specifically in cases of gastric carcinoma and polyp, in good accordance with the immunohistochemical results.

Conclusions-Low serum pepsinogen I concentrations and a low pepsinogen I : II ratio are predictive of gastric neoplasia, correlating with low tissue immunoreactivity to monoclonal antibodies raised against pepsinogen $I$ and II. For mass screening of gastric disease including carcinoma, ELISA using a one step immunoassay performed in the present study is a rapid and reliable non-radioactive method of detecting serum pepsinogen. In addition, immunohistochemical studies showed that pepsinogen production may be increased or diminished as a result of tumour histogenesis, depending on the area of origin and the processes of cell transformation and dedifferentiation. (f Clin Pathol 1995;48:364-367)

Keywords: Pepsinogen I, II, gastric cancer.

It is generally accepted raised serum pepsinogen concentrations reflect gastric diseases, in particular chronic gastritis and gastric ulcer. ${ }^{1-3}$ Pepsinogen I and II values or the pepsinogen I: II ratio have therefore been thought to be useful diagnostic markers for gastric disease, including gastric cancer. ${ }^{45}$ However, strong correlations between high serum pepsinogen levels and malignancy have not been shown. In fact, a decreased pepsinogen I value seems to be a more sensitive marker for gastric carcinoma than either the pepsinogen II level or the pepsinogen I : II ratio. An immunohistochemical study of the enzyme expression in gastric cancer showed that pepsinogen production is independent of gastric tumorigenesis. ${ }^{6}$ In order to clarify the association of pepsinogen I and II in gastric cancer, we used a rapid enzyme linked immunosorbent assay (ELISA) to measure serum enzyme levels and compared them with the tissue distribution revealed by immunohistochemistry using monoclonal antibodies.

\section{Methods}

Samples of 38 gastric carcinomas were obtained from surgical cases. Each tumour specimen was fixed in $10 \%$ formalin and embedded in paraffin wax. Tissues were then cut to $4 \mu \mathrm{m}$ thickness and stained with haematoxylin and eosin ( $\mathrm{H}$ and $\mathrm{E})$ for histopathological diagnosis. Additional equivalent sequential sections were cut and left unstained for immunohistochemical detection of pepsinogen I and II.

Human pepsinogen I and II were purified as described by Samloff ${ }^{7}$ with a minor modification. The purity of these proteins was judged by SDS-PAGE. Production of monoclonal antibodies against pepsinogen $I$ and II was done using the method of Köhler and Milstein $^{8}$ with a slight modification as reported previously. ${ }^{9}$ Immunohistochemical staining was performed using the avidin-biotin complex (ABC) method (Vectastain ABC kit, Vector Laboratories, Burlingame, California, USA). Briefly, purified monoclonal antibodies derived from mouse ascites were diluted to $1 \mu \mathrm{g} / \mathrm{ml}$ and incubated with the tissue specimens for $30 \mathrm{~min}$ at room temperature. This was followed by a second incubation with a biotinylated secondary antibody and complexed with avidinbiotin horseradish peroxidase. Sections were then stained with the chromogen 3,3'-diaminobenzidine tetrahydrochloride in $0.01 \%$ hydrogen peroxide with haematoxylin counterstain for microscopic evaluation. The specificity of the monoclonal antibodies to the gastric mucosal homogenate was determined by western immunoblotting, also with the ABC method. 


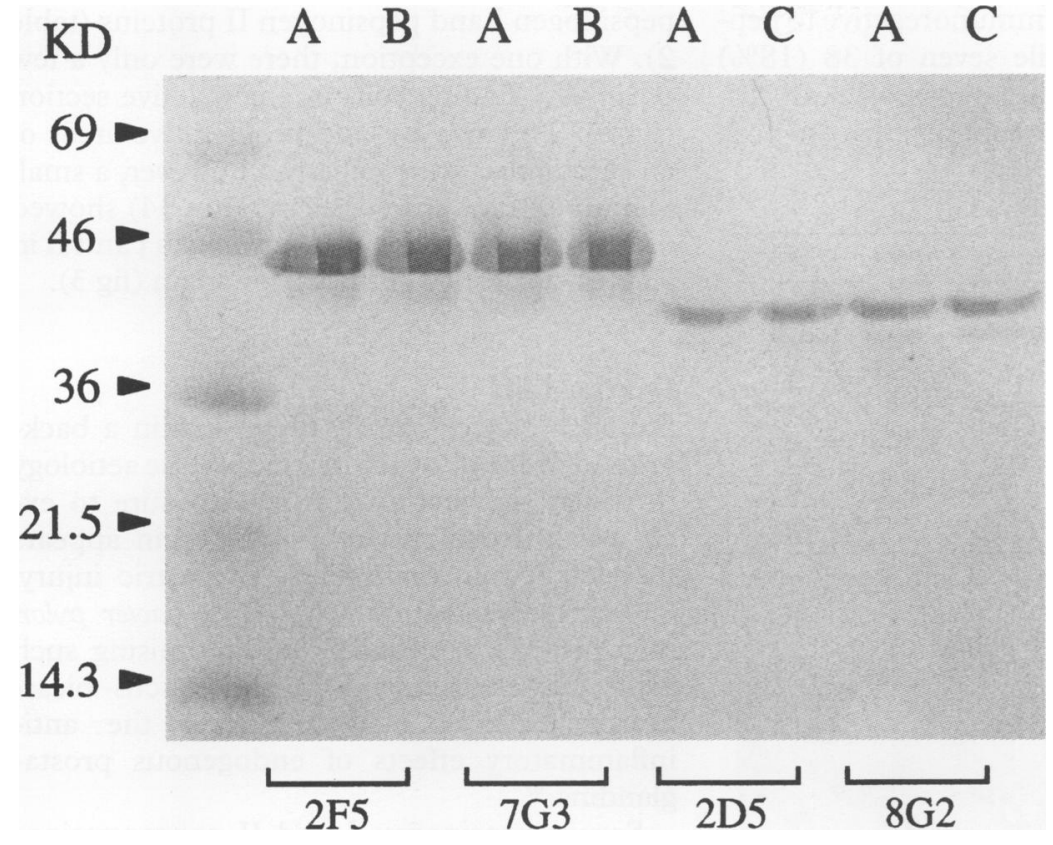

Figure 1 Western blotting, gastric mucosa homogenate $(A)$, purified pepsinogen (PG) I $(B)$, and $P G I I(C)$ were subjected to SDS-PAGE and transferred to nitrocellulose membrane. Incubation with monoclonal antibodies to PG I (2F5 and 7G3) and PG II (2D5 and 8G2).
Serum pepsinogen I and II levels were measured by ELISA in 116 healthy controls, 46 cases of gastric ulcer, 23 cases of duodenal ulcer, 44 cases of chronic gastritis (not including atrophic gastritis), 18 cases of gastric polyp consisting of tubular adenoma, and in the 38 gastric carcinoma patients from whom tissue specimens were obtained for immunohistochemical analysis. The ELISA was performed using a one step (two site immunoassay) method. In brief, 96-well microplates (Nunc, Denmark) were incubated with $0.2 \mathrm{ml}$ of either anti-pepsinogen I or antipepsinogen II (PG I, 2F5; PG II, 2D5) overnight at $4^{\circ} \mathrm{C}$. The wells were then treated with $5 \% \mathrm{w} / \mathrm{v}$ bovine serum albumin in phosphate buffered saline and incubated with peroxidase labelled anti-pepsinogen I or II (PG I, 7G3; PG II, 8G2) at $37^{\circ} \mathrm{C}$ for one hour. Using o-phenyldiamine (Sigma, St Louis, Missouri, USA) as the chromogen, absorbance was measured at 492 and $660 \mathrm{~nm}$, respectively, with a microplate reader (Corona, MTP 32, Japan).

Concentrations of pepsinogen I and II and pepsinogen I : II ratios were calculated. Statistical analyses were performed using the Fisher-Behrens test.

Results

Purified pepsinogen I and II proteins were characterised by SDS-PAGE using Coomassie brilliant blue R-250 stain. Eight and 12 monoclonal antibodies against pepsinogen $\mathrm{I}$ and pepsinogen II, respectively, were obtained, and all were subtyped to the IgG class of immunoglobulins (IgG1, G2a, or G2b). Figure 1 shows the specificity with which purified pepsinogen I and II or pepsinogens from gastric mucosal homogenate were detected with anti-pepsinogen I and anti-pepsinogen II monoclonal antibodies (MAb) following SDSPAGE. Combinations of these antibodies were used in the one step ELISA. The pepsinogen I specific MAb 2F5 and 7G3 and the pepsinogen II specific MAb 2D5 and 8G2 proved to be the most sensitive in the assay. Evaluation of a series of standards indicated that the linear range was $1-160 \mu \mathrm{g} / 1$ of pepsinogen I or II and the coefficients of variation (CV) for pepsinogen I and II were within $3.5 \%$ and $6.8 \%$, respectively, in various concentrations. The cross reactivities of pepsinogen I or II with cathepsin D or slow moving protease (SMP, cathepsin $\mathrm{E}$ ) were $<0 \cdot 1 \%$, indicating no cross reaction with each other.

Table 1 shows the mean serum pepsinogen I and II concentrations in controls and in patients with various gastric disorders. Pepsinogen I and II proteins were both detected at higher concentrations in cases of gastric and duodenal ulcers and in gastritis than in normal controls, whereas pepsinogen I concentrations were lower in patients with gastric polyp and carcinoma. The pepsinogen I : II ratio was also significantly decreased in carcinoma and polyp and also in gastric ulcer cases. The pepsinogen II specific MAb was immunoreactive to antigen in normal cardiac or pyloric glands, while the pepsinogen I specific MAb was immunoreactive to antigen in fundic glands of the stomach. These glands in normal mucosa adjacent to cancerous area were positive for pepsinogen I or pepsinogen II.

The series of gastric neoplasias examined immunohistochemically was diagnosed through serial sections according to the WHO classification as follows: papillary adenocarcinoma $(n=2)$, well differentiated tubular adenocarcinoma $(n=6)$, moderately differentiated tubular adenocarcinoma $(n=14)$, poorly differentiated tubular adenocarcinoma ( $\mathrm{n}=$ 12), signet ring cell carcinoma $(n=3)$, and mucinous adenocarcinoma $(n=1)$. With the exception of mucinous carcinoma, which showed no reactivity, there proved to be no relationship between immunoreactive pepsinogen proteins and tumour classification. There were no apparent correlations with the area of origin in the stomach or with the degree of tumour invasion. Only eight of 38 (21\%)

Table 1 Mean serum pepsinogen (PG) I and II concentrations and patients with various gastric diseases. Values are means (SD).

\begin{tabular}{llllll}
\hline Disease & $n$ & $p H$ & $P G I(\mu g / l)$ & $P G I I(\mu g / l)$ & $P G I / I I$ \\
\hline Control & 116 & $3 \cdot 6(2 \cdot 7)$ & $49 \cdot 0(30 \cdot 8)$ & $18 \cdot 1(13 \cdot 3)$ & $3 \cdot 4(1 \cdot 6)$ \\
Gastric ulcer & 46 & $4 \cdot 4(2 \cdot 9)$ & $51 \cdot 2(24 \cdot 8)$ & $23 \cdot 9(13 \cdot 1) \dagger$ & $2 \cdot 4(1 \cdot 1) \ddagger$ \\
Duodenal ulcer & 23 & $2 \cdot 2(1 \cdot 7)$ & $66 \cdot 0(22 \cdot 6) \dagger$ & $21 \cdot 9(9 \cdot 5)$ & $3 \cdot 2(0 \cdot 8)$ \\
Chronic gastritis & 44 & $3 \cdot 9(2 \cdot 7)$ & $56 \cdot 3(34 \cdot 2)$ & $20 \cdot 1(13 \cdot 0)$ & $3 \cdot 3(1 \cdot 8)$ \\
Gastric cancer & 38 & $6 \cdot 5(2 \cdot 1)$ & $41 \cdot 0(25 \cdot 7)$ & $21 \cdot 7(11 \cdot 2)$ & $1 \cdot 9(0 \cdot 9) \ddagger$ \\
Gastric polyp & 18 & $5 \cdot 7(2 \cdot 7)$ & $36 \cdot 3(18 \cdot 9)$ & $19 \cdot 9(12 \cdot 2)$ & $2 \cdot 3(1 \cdot 5) \dagger$ \\
\hline
\end{tabular}

$\dagger \mathrm{p}<0.01, \ddagger \mathrm{p}<0.001 v$ control 
gastric neoplasms were immunoreactive to pepsinogen I proteins, while seven of $38(18 \%)$ reacted to $\mathrm{MAb}$ detecting pepsinogen II; five of these cases showed immunoreactivity to both

Table 2 Pepsinogen (PG) I and II positive cases in gastric cancers.

\begin{tabular}{cllllc}
\hline Case No. & Histological diagnosis & Location & Tumour depth & $P G I$ & PG II \\
\hline 7 & Tubular, well & Antrum & Serosa & + & + \\
9 & Papillary & Body & Muscularis propria & + & + \\
12 & Tubular, poor & Antrum & Subserosa & + & + \\
15 & Tubular, poor & Body & Serosa & + & - \\
17 & Tubular, poor & Body & Muscularis propria & + & - \\
25 & Tubular, poor & Body & Muscularis propria & + & - \\
26 & Tubular, mod & Antrum & Submucosa & - & + \\
27 & Tubular, mod & Antrum & Serosa & - & + \\
34 & Signet ring & Body & Serosa & + & + \\
35 & Tubular, mod & Body & Serosa & + & + \\
\hline
\end{tabular}

well $=$ well differentiated adenocarcinoma $\bmod =$ moderately differentiated adenocarcinoma; poor $=$ poorly differentiated adenocarcinoma.

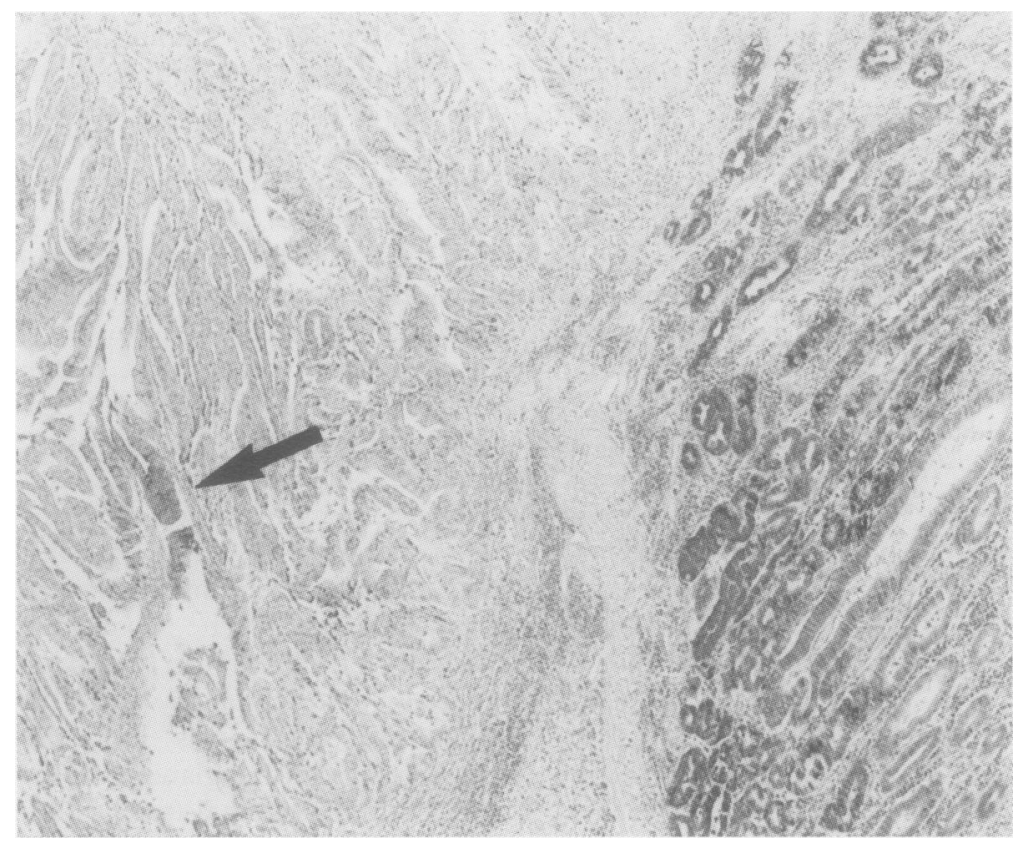

Figure 2 Immunohistochemical staining with pepsinogen (PG) II. There are a few positive cancer cells for PG II in the tumour area (arrow), whereas normal pyloric glands express PG II. (Counterstained with haematoxylin, $\times 20$.)

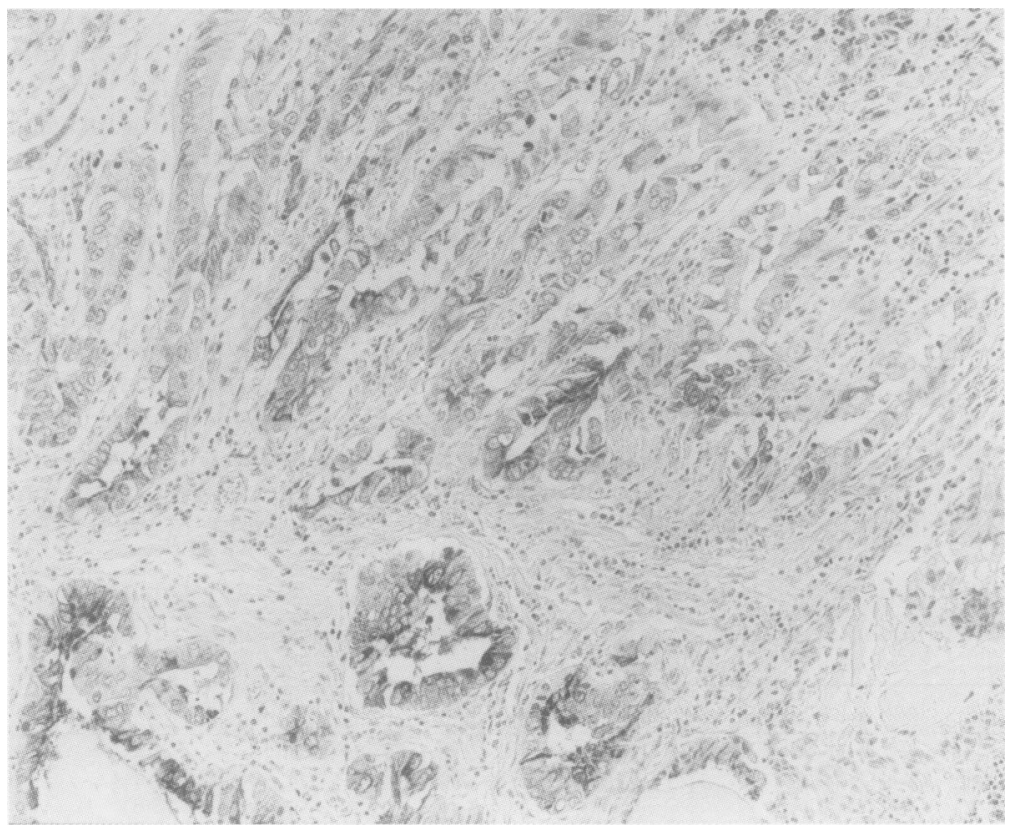

Figure 3 Immunohistochemical staining with pepsinogen (PG) I in gastric cancer. PG I expression decreased and was lost in invasive areas of cancer. (Counterstained with haematoxylin, $\times 100$.) pepsinogen I and pepsinogen II proteins (table 2 ). With one exception, there were only a few positively staining cells in any reactive section (fig 2). The invasive and proliferative areas of all carcinomas were negative; however, a small section of tumour in one case (no. 34) showed diffuse reactivity for both pepsinogen I and II in an area suggestive of the site of origin (fig 3 ).

\section{Discussion}

Stomach cancer usually arises within a background of chronic gastritis, the precise aetiology of which remains unknown. Exposure to excessive hydrochloric acid and pepsin appears to be the immediate cause of gastric injury. Concurrent infection with Helicobacter pylori may provide a means of compromising such protective mechanisms as the mucus bicarbonate barrier or by reducing the antiinflammatory effects of endogenous prostaglandins. ${ }^{10}$

Serum pepsinogen I and II concentrations and the pepsinogen I: II ratio are believed to be useful markers for chronic gastritis. ${ }^{511} \mathrm{~A}$ recent report has also shown an association between serum pepsinogen concentrations and the presence of $H$ pylor $i$ in the gastric mucosa. ${ }^{12}$ Our results agree with other published reports on pepsinogen I and II blood concentrations in various gastric disorders. ${ }^{4511}$ Significantly lower pepsinogen I: II ratios, resulting from substantially higher pepsinogen II values with only slight increases in pepsinogen I concentrations, were characteristic of gastric ulcer. Duodenal ulcer and chronic gastritis cases showed the same tendency towards increased pepsinogen I and II values, but the increases were not large enough to alter the pepsinogen I : II ratios from those in the controls. However, the pepsinogen I: II ratios were significantly decreased in blood samples from patients with stomach cancers and with polypoid tubular adenomas, a consequence of lowered pepsinogen I and raised pepsinogen II concentrations. These findings indicate that the combination of a low pepsinogen I value and a decreased pepsinogen I: II ratio may be predictive of stomach tumours.

These results are also in good accordance with the immunohistochemical studies on pepsinogen. Approximately $75 \%$ of the cases of gastric cancers examined here showed no apparent ability to produce either pepsinogen I or pepsinogen II in detectable amounts. The carcinoma cases used in the present study were not associated with widespread gastric atrophy. Previous immunohistochemical surveys have shown variable reactivity ranging from $2 \cdot 8$ $75.0 \%$ and $17 \cdot 8-29 \cdot 7 \%$ to pepsinogen $I$ and pepsinogen II proteins, respectively. ${ }^{41-15}$ The reasons for the variability in pepsinogen I and II expression may be differences in the antibodies used or in the staining conditions. Neither did these studies give any details as to histological classification or lesion differentiation. The chief cells and mucous neck cells of the fundic glands of the stomach produce both pepsinogen I and pepsinogen II, but pepsinogen II is also secreted by the pyloric and Brunner's glands in the 
proximal duodenum. ${ }^{16}$ Additionally, pepsinogen I production appears to be significantly associated with the production of pepsinogen II. ${ }^{6}$ While, as previously mentioned, there was no correlation between tumour classification or degree of differentiation, the differences in pepsinogen expression may be explained by the histogenesis of the neoplasm. Tumours originating from the pyloric area and producing both pepsinogen I and pepsinogen II suggest that neoplastic cells may gain the ability to produce pepsinogen through transformation or dedifferentiation. Conversely, the ability to express pepsinogen may also be lost during the processes of transformation or dedifferentiation, as may be illustrated by case no. 34 (fig 3). This tumour was positive for both pepsinogen I and pepsinogen II only within a fairly local and more well differentiated area; immunoreactivity appears to be lost in the less organised and anaplastic regions. Serum pepsinogen values reflect the same trends in that the polypoid tubular adenomas show a suppressed pepsinogen production compared to controls. The serum pepsinogen concentrations in patients with gastric cancers are higher relative to those with adenomas, approaching the mean control values.

1 Samloff IM. Pepsinogens, pepsins and pepsin inhibitors. Gastroenterology 1971;60:586-604.

2 Samloff IM, Secrist DM, Passaro EJ. A study of the re- lationship between serum group I pepsinogen levels and gastric acid secretion. Gastroenterology 1975;69:1196-200. 3 Brady CE, Hadfield TL, Hyatt JR, Utts SJ. Acid secretion and serum gastrin levels in individuals with Campylobacter pylori. Gastroenterology 1988;69:83-90.

4 Huang SC, Miki K, Furihata C, Ichinose M, Shimizu A, $\mathrm{Oka} \mathrm{H}$. Enzyme-linked immunosorbent assays for serum pepsinogens I and II using monoclonal antibodies-with pepsinogens $I$ and II using monoclonal antibodies-with data on peptic ulcer

5 Miki K, Ichinose M, Kawamura N, et al. The significance of low serum pepsinogen levels to detect stomach cancer of low serum pepsinogen levels to detect stomach cancer
associated with extensive chronic gastritis in Japanese associated with extensive chronic gastritis
subjects. $¥ p n \mathcal{F}$ Cancer Res 1989;80:111-4.

6 Huang SC, Miki K, Sano J, et al. Pepsinogens I and II in gastric cancer: an immunohistochemical study using

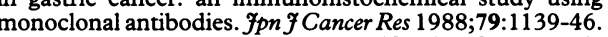

7 Samloff IM. Pepsinogen I and II: purification from gastric mucosa and radioimmunoassay in serum. Gastroenterology 1982;82:26-33.

8 Köhler G, Milstein C. Continuous cultures of fused cells secreting antibody of predefined specificity. Nature 1975; 256:495-7.

9 Konishi N, Kitahori Y, Shimoyama T, Lin JC, Hiasa Y. Monoclonal antibody against rat renal cell tumor-associated antigen as a new tool for the analysis of renal sociated antigen as a new tool for the analysis
tumorigenesis. $\mathfrak{f p}_{p} \mathfrak{f}$ Cancer Res 1989;80:771-7.

10 Vaira D, Holton J, Barbara L. Helicobacter pylori and gastroduodenal disease. Gastroenterol Int 1991;4:70-6.

11 Samloff IM, Varis K, Ihamaki T, Siurala M, Rotter JI. Relationship among serum pepsinogen I, serum pepsinogen II and gastric mucosal histology: a study in relatives of patient with pernicious anemia. Gastroenterology 1982;83:204-9.

12 Biasco G, Paganelli GM, Vaira D, et al. Serum pepsinogen I and II concentrations and IgG antibody to Helicobacter pylori in dyspeptic patients. F Clin Pathol 1993;46:826-8.

13 Reid WA, Valler MJ, Kay J. Aspartic proteinases in gastric carcinomas. In: Kostka V, ed. Aspartic proteinases and their carcinomas. In: Kostka V, ed. Aspartic proteinases and

inhibitors. Berlin: Walter de Gruyter, 1985;:519-23.
14 Busby-Earle RMC, Williams ARW, Piris J. Pepsinogens in gastric carcinomas. Hum Pathol 1986;17:1031-5.

15 Stemmermann GN, Samloff IM, Hayashi T. Pepsinogens I and II in carcinoma of the stomach: an immunohistochemical study. Appl Pathol 1986;3:159-63.

16 Samloff IM, Liebman WM. Cellular localization of the group II pepsinogens in human stomach and duodenum by immunofluorescence. Gastroenterology 1973;65:36-42. 